\title{
IMPROVING SERVICE QUALITY IN TURKISH HEALTHCARE SYSTEM: THE ROLE OF MEDICAL TECHNOLOGY
}

\author{
Mehmet Şahin GÖK
}

\begin{abstract}
This study aims to examine the role of medical technology for improving service quality. For this purpose we empirically analyze the relationship between the efficiency of medical technology and perceived service quality in Turkish healthcare services. Accordingly, inefficiency causes of medical technology are also discussed in this study. Data Envelopment Analysis (DEA) is applied to analyze the medical technology-based efficiencies of teaching hospitals in Turkey for the study years from 2008 to 2010. Data concerning 40 teaching hospitals are obtained from Annual Statistical Health Report and Turkish Ministry of Health (TMoH). This explanatory study provides the evidence that teaching hospitals might be able to improve both quality and efficiency of their services by effective utilization of existing medical technology. We find that efficient hospitals also provide high quality services compared to their inefficient counterparts. According to these results, hospital administrators could improve perceived service quality by increasing the efficiencies of their existing medical technology. This study also suggests practical implications for the reallocation of medical devices in order to meet patient demand. Policy makers should focus on monitoring the effective utilization of existing medical capacity. This study contributes to the field of healthcare management research by applying the DEA model to the relationship between medical technology and service quality. Furthermore, this study provides several significant findings regarding inefficiency causes of medical technology and suggestions for quality improvements.
\end{abstract}

Keywords Medical technology; Service quality; Inefficiency; Data envelopment analysis; Teaching hospitals

JEL classifications: C14, C23, I1 1

\section{INTRODUCTION}

In today's highly competitive healthcare sector, one of the most essential targets of hospitals is the effective utilization of their existing resources in pursuit of providing high quality of care. Since inefficiency has contributed to rising costs, hospital administrators focus on the effective utilization of resources. The importance of scarce resources such as high-tech medical devices has improved in this environment. Furthermore, financing of medical

\footnotetext{
${ }^{1}$ Gebze Institute of Technology, Faculty of Business Administration, Turkey. E-mail: sahingok@gyte.edu.tr
} 
technology has become an essential issue for healthcare policy makers due to their acquisition costs. Since teaching hospitals intensely use high-tech medical devices, the expenditures of these hospitals rapidly increase. High medical technologic treatments can also increase health service cost of teaching hospitals. Faced with rising cost and scarce resources, teaching hospitals are struggling to provide a high quality patient care as well as effective utilization of medical technology (Amado and Santos, 2009).

Balancing cost, quality and efficiency in healthcare industry involves difficult management trade-off considerations. In this context, healthcare providers are under an increasing pressure to create and maintain a positive and supportive service climate in their organization (Lanjananda and Patterson, 2009). Mutter et al. (2010) argued that service quality and efficiency improvements can be achieved simultaneously by reducing expensive and subordinate complications. It is also possible that perceived service quality might be improved by effectively using medical technology and other resources in order to serve growing demand.

In this regard, technology is an indicator of quality for performance assessment. Thereby, medical technology primary aims to improve quality of care by using medical devices (Gerhardus, 2003). These are covering any instrument, appliance, materials or other tools which are used alone or in combination for the purpose of diagnosis, prevention, monitoring or treatment (Ghodeswar and Vaidyanathan, 2007). In fact, technology does more than it is intended to do: it has a broad array of effects in health care services (Boenink, 2011). Hightech medical devices are directly related to diagnosis and treatments. Hospitals can provide advanced services to the patients by using innovative medical technology. Since technology provides improvements on the new treatment applications and new products, effective implementation of medical technology is associated with improved hospital efficiency.

Most recently Sorenson and Kanavos (2011) investigate the effectiveness of the medical technology procurement processes. Similarly, most of the studies (Liu et al., 2009; Jönsson, 1997) focus on the financial aspects of medical technology. On the other hand, medical devices play an increasingly central role in clinical practice bringing healthcare and quality of life for patients and hospitals (Sorenson and Kanavos, 2011; Geisler, 2011). Thus healthcare policy makers should take into account the "consumer-driven" and "consumer-oriented" healthcare services (Dwarswaard et al., 2011). Despite this importance, it remains uncertain 
whether medical technologies are being effectively utilized for patients. Thus, it is imperative to examine utilization effectiveness of medical technology from both hospital and patient perspectives.

In this respect, the aim of this study is to investigate the impacts of medical technology on perceived service quality of teaching hospitals. In other words, we seek to examine whether efficient teaching hospitals are associated with different levels of perceived service quality than inefficient hospitals. In this study, we define hospitals as efficient based on their effective utilization of medical technology. Data envelopment analysis (DEA) is used to analyze the efficiencies of teaching hospitals for the study years from 2008 to 2010. Cullinane et al. (2004) indicated that efficiencies should be evaluated with data over more than a single period of time in order to avoid biases. In this study, efficiency analyses of teaching hospitals across multiple time periods allows for a comprehensive and unbiased results.

This study provides some guidance about the affects of medical technology on the perceived service quality of teaching hospitals. Moreover it shows opportunities for improving perceived service quality and the reallocation of ineffectively utilized medical devices in order to better meet demand. The structure of the paper is organized as follows. Second section provides the brief information about the teaching hospitals and medical technologies in Turkey. The data sources and methods are presented in the third section. Empirical results are reported in the fourth section. Finally, the last section provides discussion and policy implication remarks.

\section{TEACHING HOSPITALS IN TURKEY}

Healthcare services in Turkey are provided to the majority of the population by Turkish Ministry of Health (TMoH). The TMoH was founded in 1920 and aims to provide healthcare with universal coverage. Teaching hospitals are significantly larger than non-teaching hospitals in terms of employee, services, financial budget and medical technologies. Technology investments of teaching hospitals rapidly increase to provide advanced treatments. Moreover, these hospitals focus on applied clinical and biomedical research that intern the ability of observation, diagnoses and treatment of patients by using high-tech medical devices (Langabeer, 2008).

The annual healthcare service cost for the Turkish teaching hospitals was 2,223 million $\$$ in 2010 while it was 1,607 million \$ in 2009 and 1,404 million \$ in 2008. The total number of 
inpatients for teaching hospitals was 1,509,484 in 2010 while it was 1,462,690 in 2009 . Besides, the number of beds increased to the 35,001 in the proportion of $17.01 \%$ when comparing the 2008 to 2010 . Similarly, in 2010, number of intensive care beds increased to the 3,706 in the proportion of $19.11 \%$. The number of surgical operations was $1,126,066$ for teaching hospitals in 2010. On the other hand, the proportion of surgical operations to the number of visits was $5.6 \%$ for teaching hospitals while it was 3.1\% for non-teaching hospitals. Moreover the occupancy ratio and the average length of stay were 72.9 and 6.2 , for teaching hospitals respectively, while they were 57.6 and 3.2 for non-teaching hospitals (Mollahaliloglu et al, 2010). In parallel with the developments in the global healthcare industry, medical technology utilization and health service costs of teaching hospitals are rapidly increasing in Turkey.

In this regard, investments on technological capacity of Turkish teaching hospitals have been increased in recent years (Aydın et al., 2009). These high-tech medical devices provide clinical information to the healthcare providers. Physicians are able to access and analyze biomedical data that are gathered by new medical devices. The adaptation and utilization of medical technology brings together an improvement in the quality of care and effectiveness of clinicians. Healthcare providers aim to improve the service quality by using high-tech medical devices. However perceived value of care may still be low due to the other care factors such as state of the art of medicine. In case, physicians often play an influential role in the utilization of high-tech medical devices for patients needs. From the patients' perspective, maintenance of quality might be provided by reducing undesired outcomes and mistakes in the whole spectrum of care (Ozcan, 2009). Therefore, patients' perceptions can be positively influenced by using high-tech medical devices in the treatment processes by qualified physicians (Geisler, 2011). Medical technologies may contribute the service quality improvement. Ultimate outcomes and other benefits of medical technologies might enhance the quality of care in teaching hospitals.

According to the dynamic changes in teaching hospitals, operations are affected by increased demand for quality and efficiency. Sellers-Rubio and Mas-Ruiz (2007) indicate that costcutting adaptations in the high-tech medical devices for efficiency improvements might have a negative effect on the perceived service quality. Contrary to this, Bosworth et al. (2005) argued that progress in quality improvement contribute the effectiveness and efficiency growth. 
Total Quality Management (TQM) can be seen as an appropriate implementation to improve both efficiency and service quality of healthcare institutions. Moreover, TQM create a systematic approach for designing healthcare service process that will exceed and at least meet the patient expectations. Many of the Turkish teaching hospitals have implemented TQM programs for effective utilization of resources (Aydın et al., 2009). This program can also contribute effective utilization of high-tech medical devices for improving the care processes. The objective of TQM is to increase patients' satisfaction in pursuit of reducing cost, and increasing quality and efficiency of teaching hospitals.

\section{DATA}

This study focuses on the teaching hospitals which are affiliated to the Turkish Ministry of Health (TMoH). Teaching hospitals are defined as those with medical residents that receive specialized medical training such as having residency for becoming a specialized physician. The data are obtained from Annual Statistical Health Report published by the TMoH for the period of 2008 to 2010. In 2008 to 2010 , there were 47 teaching hospitals in Turkey. After eliminating some hospitals due to the missing data, the sample is composed of 40 teaching hospitals. Data regarding perceived service quality of these hospitals are obtained from the Patient Satisfaction Index presented by Performance Management and Quality Improvement Department of TMoH. This index refers to the patients' satisfaction with the services delivered by teaching hospitals.

Survey implementation had been designated for inpatients and outpatients in order to establish patient satisfaction index. The surveys considered both the patients and their families within the process. The aim of this survey is to explain the public opinion about welfare and how the healthcare results are perceived by the patients. The satisfaction measurement is carried out regularly, once in a month; however the results are evaluated once in every four months. These studies are carried out by the hospitals under the responsibility of the Performance and Quality Units (Aydın et al., 2009).

Since this study aims to examine the medical technology of teaching hospitals, only technological devices are chosen as the input variables in this study. These variables are defined as following:

- Number of Magnetic Resonance Imaging (MRI) devices 
- Number of Computerized Resonance Imaging (CRI) devices

- Number of Hemodialysis devices

- Number of Ultrasound devices

- Number of Doppler Ultrasound devices

- Number Echocardiography (ECO) devices

These high-tech medical devices are selected for study because they are the only ones for which comparative data was available for determining medical technology. These variables were also used in prior studies. For example, Kontodimopoulos and Niakas (2005) analyzed the efficiencies of dialysis units in the technological perspective. They used the number of hemodialysis devices as an input variable. Similarly, Irwin et al. (1998) used the ultrasound devices in order to categorize hospital services by 'high-tech' rating corresponding to the level of technological sophistication of the technology associated with the service. On the other hand, Ghodeswar and Vaidyanathan (2007) define the most important medical technologies in their study which examine the organizational adaptation of medical technology. These authors indicated that MRI, CRI and ECO devices are categorized in the routine used medical devices. In parallel with this, Retzlaff-Roberts et al. (2004) investigate the utilization of efficiency of healthcare services and they define the number of MRI device as health input variable. Following to the previous studies and concerning the available limited data, above mentioned devices are selected as input variables in the current study.

Hollingsworth (2008) summarized the intermediate outputs and case-mix adjusted outputs that were used in the past studies. In this paper case-mix adjusted outputs are not included as variables because of the unavailability of data. However intermediate outputs are used to describe the individual hospital output variables. In our empirical study four outputs which are directly related to the utilization of technological capacity were chosen to analyze the efficiencies of teaching hospitals. These output variables are defined as following:

- Number of patients

- Number of discharge

- Total number of surgery

- Average length of stay

Butler and Li (2005) indicate that surgeries require different combination of specialized and technological equipment and staff. Number of patients, number of discharge and average 
length of stay measure the utilization of institution facilities for patients. Average length of stay also provides a usage frequency of hospital resources. We used these output variables in order to determine the utilization of technological capacity for patients. In other words, these outputs are used to analyze the patient related technological resources of hospitals.

Previous studies have indicated that the number of DMUs (in this case the number of teaching hospitals) should be greater than the multiplication of the numbers of inputs and outputs (Dyson et al., 2001; Camanho and Dyson 2006). In the current study, the numbers of DMUs are over to this constraint. Descriptive statistics regarding the output and input variables used in our analysis are presented in Table 1.

Table I. Descriptive Statistics of Input and Output Variables

\begin{tabular}{lcc}
\hline & Mean & Std. Dev. \\
\hline Inputs & 5.76 & \\
\# of MRI devices & 7.62 & 1.59 \\
\# of CTI devices & 73.98 & 1.76 \\
\# of Hemodialysis devices & 21.94 & 23.15 \\
\# of Ultrasound devices & 16.37 & 8.32 \\
\# of Doppler Ultrasound & 8.45 & 5.32 \\
devices & & 2.65 \\
\# of Echocardiography devices & & \\
& 680386.04 & \\
Outputs & 24078.39 & 52249.5 \\
\# of patients & 7346.29 & 1493.44 \\
\# of discharge & 6.46 & 852.11 \\
Total number of surgery & & 4.38 \\
Average length of stay &
\end{tabular}

\section{EFFICIENCY ANALYSIS}

In the healthcare sector, Data Envelopment Analysis (DEA) has been the most frequently used technique for measuring efficiency (Hollingsworth, 2008). DEA is a mathematical programming technique that analyzes the relative efficiencies of peer DMUs with respect to the multiple inputs and outputs. As Kumar and Gulati (2008) indicated, DEA draws an efficiency frontier over the data points to evaluate the efficiency of each DMU relative to this frontier.

There are various DEA models that have been developed to examine the efficiency, including input- and output-oriented, and CRS (constant return to scale) and VRS (variable return to scale). Generally, Constant Return to Scale (CRS) model is suggested for efficiency analysis in the healthcare institutions (Weng et al., 2009). The reason of choosing the CRS model for 
examining the hospital efficiencies is to analyze the efficiency in the absence of any scale or congestion effects. Since number of determined technological devices selected as input variables, input-oriented CRS model is implemented for analyzing the efficiencies of teaching hospitals in this study.

\section{IV.I. Empirical Results}

The average efficiency scores and perceived service quality index of teaching hospitals are summarized in Table 2. The average efficiency score of teaching hospitals in 2008 was 0.56 which increased to 0.72 in 2010 for an improvement of $28.5 \%$. The number of efficient hospitals also increased from 4 (2008) to 12 (2010).

Table II. Efficiency and Quality Statistics of Teaching Hospitals ( $\mathrm{n}=40)$

\begin{tabular}{lccc}
\hline & 2008 & 2009 & 2010 \\
\hline \multirow{2}{*}{ Average Efficiency Scores } & 0.56 & 0.59 & 0.72 \\
\multirow{2}{*}{ Average Perceived Service Quality Scores } & $(0.23)$ & $(0.21)$ & $(0.22)$ \\
& 0.86 & 0.86 & 0.85 \\
& $(0.07)$ & $(0.07)$ & $(0.06)$ \\
\hline
\end{tabular}

* Standard deviations of efficiency scores were given in the parenthesis.

Interastingly, average technical efficiencies significantly increase while there is no significant change on perceived service quality scores. In other words, average efficiencies of teaching hospitals tend to increase in the study period. However, similar improvement trend is not observed for the perceived service quality scores.

Although average efficiencies of teaching hospitals tend to increase there is still room for efficiency improvement in order to eliminate inefficiencies. The degree of inefficiency is found by subtracting the efficiency score from 1.00. This difference point out the percentage of the total amount of hospital inputs could reduce radially, holding outputs constant (Valdmanis, 2010). In our case, this difference indicates the inefficiency degree of medical technology for teaching hospitals. Average inefficiency of medical technology in 2008 was 44 percent [1-0.56] which reduced to 28 percent [1-0.72] in 2010. Therefore, teaching hospitals eliminated the inefficient utilization of existing medical technology for an improvement of 36.3 percent in the period of 2008 to 2010 .

DEA provides not only efficiency scores of hospitals but also slack analysis. The slacks can express hospital administrators' attention to areas where inefficiency exists and adjust 
accordingly to optimize efficiency and quality of care (Sherman, 1984). Therefore, inefficiency analysis can provide guidelines to derive the optimal level of inputs for each hospital as well as identifies the ineffective utilization of medical technology. Inefficiency analysis also shows hospitals how much their existing medical technology should be improved as compared with efficient teaching hospitals.

Controlling the percentages of slacks provides the greater opportunity to assess efficiency measurements that are better reflections of expected patterns of potential improvements (Avkiran et al., 2008). Table 3 shows the percentage inefficient utilization rate of medical devices for the inefficient teaching hospitals in contrast to those on the efficiency frontier for the three years examined. The percentage inefficient utilization rate of medical devices is calculated as follows. As an example, slack value of MRI device is 0.48 for one hospital (Hospital-A) in our sample. Existing number of MRI device for this hospital is 8. Here we can find percentage inefficient utilization rate of MRI device [(slack value of device x 100) / existing number of device] for this hospital. Then, inefficient utilization rate of MRI device is found for other hospitals in a similar calculation. The average of these inefficient rates composes the percentage inefficient utilization rate of MRI device. Percentage inefficient utilization rate of each device is calculated in a similar manner.

Almost all of the inefficient utilizations of medical devices reduced in the study periods. Average inefficiency of CTI devices in 2008 was $14.10 \%$ which reduced to $8.09 \%$ in 2010 for an improvement of $42.62 \%$. Similarly, utilization effectiveness of MRI devices, hemodialysis devices, ultrasound devices and doppler ultrasound devices were increased for an improvement of $0.35 \%, 39.45 \%, 56.16 \%$ and $60.01 \%$, respectively. Utilization effectiveness of echocardiography increased on the period of 2008 to 2009 for improvement of $57.92 \%$. However on a negative note, the average inefficient utilization of echocardiography devices in 2008 was $7.63 \%$ which increased to $13.66 \%$ in 2010 representing a retrogressive of $79.03 \%$.

Table III. Inefficient Utilization Rate of Technological Devices (\%)

\begin{tabular}{lccc}
\hline & 2008 & 2009 & 2010 \\
\hline MRI devices & 5.68 & 6.75 & 5.66 \\
CTI devices & 14.10 & 8.67 & 8.09 \\
Hemodialysis devices & 12.37 & 7.43 & 7.49 \\
Ultrasound devices & 9.65 & 4.27 & 4.23 \\
Doppler Ultrasound devices & 10.58 & 6.48 & 5.98 \\
Echocardiography devices & 7.63 & 3.21 & 13.66 \\
\hline
\end{tabular}


In a secondary analysis, the relationship between the effective utilization of medical capacity and perceived service quality provided by the hospitals in our sample is assessed. The relatively small number of teaching hospitals in each year $(n=40)$ implies that a large fraction would become fully efficient if contemporaneous frontiers were to be established for each year. That is, by pooling the three-year data, a larger sample $(n=120)$ would be obtained for teaching hospitals. The pooled data is used to investigate the relationship between the effective utilization of medical capacity and perceived service quality instead of separate analysis for each year.

Then, teaching hospitals in our sample are categorized as poor and high utilized medical capacity hospitals according to their utilization effectiveness of medical capacity. For this purpose, data has been mean centered and, then, split into poor and high utilized medical capacity hospitals. Poor medical technology hospitals are classified as ineffectively utilize their medical capacities $(n=56)$. While high medical technology hospitals are classified as effectively utilize their medical capacities $(n=64)$. Utilization effectiveness of medical capacity is calculated as follows. The slack values and inefficiency rate of each medical device are calculated. As the example of Hospital-A, 7.52 MRI devices (subtracting slack value from existing number of device) was effectively utilized. Here we can find percentage utilization effectiveness of MRI device [(number of effectively utilized device x 100) / existing number of device] for this hospital. Utilization effectiveness of each device is calculated in a similar manner. Then, utilization effectiveness of medical technology for each hospital is obtained by calculating the average scores of utilization effectiveness for each device. Then, the relationship between efficiency and perceived service quality is examined for these two groups. The findings are given in Table 4.

Table IV. Correlation between Efficiency and Perceived Service Quality

\begin{tabular}{lcc}
\hline & $\begin{array}{c}\text { Poor Utilized } \\
\text { Technological Capacity } \\
\text { Hospitals } \\
(\mathrm{n}=56)\end{array}$ & $\begin{array}{c}\text { High Utilized Technological } \\
\text { Capacity Hospitals } \\
(\mathrm{n}=64)\end{array}$ \\
\hline $\begin{array}{l}\text { Efficiency - Perceived } \\
\text { Service Quality Relationship }\end{array}$ & nonsignificant & $0.269^{*}$ \\
\hline $\begin{array}{l}\text { Average Score of Perceived } \\
\text { Service Quality }\end{array}$ & 0.72 & 0.93 \\
\hline
\end{tabular}

\footnotetext{
* Significant at 0.05 level
} 
Table 4 demonstrates that there is a significant positive correlation $(r=0.269, \mathrm{p}<0.05)$ between efficiency and perceived service quality for hospitals that effectively utilize their medical capacity. However, no significant correlation was found for other group of teaching hospitals. According to the results, teaching hospitals that effectively utilize their medical capacity might also increase the perceived service quality.

\section{DISCUSSION}

Utilization efficiency of medical technology is one of the major managerial objectives of teaching hospitals. The efficiencies of teaching hospitals are analyzed across multiple time periods. Thereby, results enable a rich benchmarking for medical technology utilization. The results can also be used for planning management activities in advance to enhance the technical efficiency and service quality.

The data for the period of 2008 to 2010 showed a significant improvement in technical efficiency of teaching hospitals in Turkey. Since the average efficiency score improved from 0.56 in 2008 to 0.72 in 2010 (see in Table 2), the average efficiency score increased by $28.5 \%$. In achieving this significant improvement, the effective utilization of medical devices also increased in teaching hospitals.

Although, most of the inefficient utilization of medical devices reduced in the study period, medical technologies might be reduced while maintaining the same care services. In other words, inefficient teaching hospitals can improve their performance by decreasing their medical technology. However, considering the missions of teaching hospitals, reduction of medical capacity does not seem to be a realistic solution. Similarly, Marceau and Basri (2001) state that healthcare policy makers should consider the benefits of medical technologies for developing their capabilities without focusing on cost. Therefore policy makers must concentrate on the monitoring of the effective utilization of existing medical capacity by using evaluation tools. They might perform the quantitative models such as operational scheduling for high-tech medical devices. Also excesses of medical technology might be taken into service for the private care centers. In this way, teaching hospitals do not only use their medical technologies for the welfare of patients, but also they can attain financial support for their budgets. However health care administrators should inevitably take into account the institutional factors and regulations in order to perform operational scheduling for medical technology. The use of linear programming, simulation modeling and other mathematical tools will support a broad range of processes, including high-tech medical 
device scheduling, patient routing, service delivery, and department or resource location analysis (Gok and Sezen, 2011; Langabeer, 2008). Furthermore, healthcare policy makers should focus on the development of a regional based online system among efficient and inefficient teaching hospitals aiming the better distribution of medical technology with adequate coverage of all healthcare needs for patients. These suggestions should be considered by teaching hospital administrators in advance to enhance the operational efficiency and increase perceived service quality for teaching hospitals.

One of the main purposes of this research is to understand if teaching hospitals improve perceived service quality by effective utilization of medical technology. We found that highefficient hospitals perform at higher perceived service quality. The significant relationship was found between efficiency and perceived service quality for these hospitals. However there is not any significant relationship between efficiency and quality for low-efficient hospitals. Accordingly, hospitals that ineffectively utilize the medical technologies also tend to have low level of perceived service quality. (Average score of perceived service quality is 0.73 for poor utilized technological capacity hospitals while 0.93 for its counterparts. see in Table 4). Thus, low-efficient hospitals can improve perceived service quality by eliminating the inefficiencies of medical technologies. This result need to be addressed by hospital administrator or policy makers in order to effectively utilization of existing high-tech medical devices. Furthermore, quality of care has a fundamental role in terms of providing continuous support for patients and their families. This continuous relationship is essential to built trust between healthcare administrators and patients (Amado and Santos, 2009). Therefore teaching hospital administrators should take this aspect into account and aim to increase efficiency as well as perceived service quality.

Our methodological approach presents empirical findings to healthcare policy makers and hospital administrators about the relationship between utilization efficiencies of high-tech medical devices and service quality. For instance, perceived service quality can be improved by increasing the technical efficiency as hypothesis by TQM approach (Helper and Kiehl, 2004). In other words, increasing the utilization efficiencies of existing medical technology might positively affect the service quality perceptions of patients. For other hospitals, reducing medical technology services might also improve the efficiency level, therefore perceived service quality. These policy options should be taken into account by teaching hospital administrators by considering the physical characteristics of hospitals, patient needs and other requirements of health care environment. The examination of teaching hospitals 
efficiency via DEA employed in this paper might not be able replace the one-side evaluation conducted by Turkish Ministry of Health. However, alternative policy options might be provided for increasing both efficiency and service quality of teaching hospitals. Thereby, this study is a tool worthy of consideration by teaching hospital administrations and healthcare policy makers for improvement activities and reforms.

This study has a number of limitations that require further research. Firstly, teaching hospitals are major research and care centers. Thus, their inputs are difficult to measure and quantify. Some inputs of these hospitals were left out of this analysis. However, this study mainly focuses on the medical technology resources of teaching hospitals. Therefore, efficiency results are driven on this concept. Future research could attempt to find a proxy for other aspects of teaching hospitals. Additionally, extending the research period beyond 3 years will perhaps shed even more light on the relationship between medical technology and perceived service quality. Researches on these issues represent an important step towards improving the contribution of service quality and efficiency assessment in practice. 


\section{REFERENCES}

Amado, C.A.E.F. \& Santos, S.P. 2009. Challenges for performance assessment and improvement in primary health care: The case of the Portuguese health centres. Health Policy, 91: 43-56.

Avkiran, N.K., Tone, K. \& Tsutsui, M. 2008. Bridging radial and non-radial measures of efficiency in DEA. Annals of Operations Research, 164: 127-138.

Aydın, S., Demir, M., Guler, H., Ozturk, A., Tarhan, D., Demir, B. \& Kapan, S.H. 2009. Institutional Performance and Quality Applications in Healthcare. Ankara: Lazer Ofset Publications.

Boenink, M. 2012. Debating the Desirability of New Biomedical Technologies: Lessons from the Introduction of Breast Cancer Screening in the Netherlands. Health Care Analysis, 20(1): 84-102.

Bosworth, D., Massini, S. \& Nakayama, M. 2005. Quality change and productivity improvement in the Japanese economy. Japan and the World Economy, 17: 1-23.

Butler, T.W. \& Li, L. 2005. The utility of returns to scale in DEA programming: An analysis of Michigan rural hospitals. European Journal of Operational Research, 161(2): 469-477.

Camanho, A.S. \& Dyson, R.G. 2006. Data envelopment analysis and malmquist indices for measuring group performance. European Journal of Operational Research, 161: 432-446.

Cullinane, K., Ji P. \& Wang, T. 2004. An application of DEA Windows Analysis to container port production. Review of Network Economics, 3(2): 184-206.

Dwarswaard, J., Hilhorst, M. \& Trappenburg M. 2011. The Doctor and the Market: About the Influence of Market Reforms on the Professional Medical Ethics of Surgeons and General Practitioners in The Netherlands. Health Care Analysis, 19(4): 388-402.

Dyson, R.G., Allen, R., Camanho, A.S., Podinovski, V.V., Sarrico, C.S. \& Shale, E.A. 2001. Pitfalls and protocols in DEA. European Journal of Operational Research, 132(2): 245-259. Geisler, E. 2011. Linking medical technology and quality of healthcare delivery: An explanatory study of stage model. International Journal of Healthcare Technology and Management 12(3/4): 199-214.

Gerhardus, D. 2003. Robot-assisted surgery: The future is here. Journal of Healthcare Management, 48(4): 242-251. 
Ghodeswar, B.M. \& Vaidyanathan, J. 2007. Organizational Adoption of Medical Technology in Healthcare Sector. Journal of Service Research, 7(2): 57-81.

Gok, S.M. \& Sezen, B. 2012. Capacity inefficiencies of teaching and non-teaching hospitals. Service Industries Journal, 32(14): 2307-2328.

Helper, S. \& Kiehl, J. 2004. Developing supplier capabilities: Market and non-market approaches. Industry and Innovation, 11: 89-107.

Hollingsworth, B. 2008. The measurement of efficiency and productivity of health care delivery. Health Economics, 17(10): 1107-1128.

Irwin, J.G., Hoffman, J.J. \& Lamont, B.T. 1998. The effect of the acquisition of technological innovations on organizational performance: A resource-based view. Journal of Engineering and Technology Management, 15: 25-54.

Jönsson, B. 1997. Economic evaluation of medical technologies in Sweden. Social Science \& Medicine, 45(4): 597-604.

Kontodimopoulos N. \& Niakas D. 2005. Efficiency measurement of hemodialysis units in Greece with data envelopment analysis. Health Policy, 71: 195-204.

Kumar, S. \& Gulati, R. 2008. An Examination of Technical, Pure Technical and Scale Efficiency in Indian Publick Sector Banks using Data Envelopment Analysis. Eurasian Journal of Business and Economics, 1: 33-69.

Langabeer, J.R. 2008. Health care operations management: A quantitative approach to business and logistics. Massachusetts: Jones and Bartlett Publishers.

Lanjananda, P. \& Patterson, P.G. 2009. Determinants of customer-oriented behavior in a health care context. Journal of Service Management, 20: 5-32.

Liu, G.G., Fukuda, T., Lee, C.E., Chen, V. \& Zheng, Q. 2009. Evidence-based decision making on medical technologies in China, Japan, and Singapore. Value in Health, 12(3): 1217.

Marceau, J. \& Basri, E. 2001. Translation innovation systems into industrial policy: The healthcare sector in Australia. Industry and Innovation, 8(3): 291-308.

Mollahaliloglu, S., Basara, B.B. \& Eryilmaz Z. 2011. Health Statistics Year Book 2010. Ankara: Kalkan. 
Mutter, R., Valdmanis V. \& Rosko, M. 2010. High versus lower quality hospitals: A comparison of environmental characteristics and technical efficiency. Health Services and Outcomes Research Methodology, 10: 134-153.

Ozcan, Y.A. 2009. Quantitative Methods in Health Care Management: Techniques and Applications. San Francisco: Jossey Bass.

Retzlaff-Roberts, D., Chang, C.F. \& Rubin, R.M. 2004. Technical efficiency in the use of health care resources: A comparison of OECD countries. Health Policy, 69: 55-72.

Sellers-Rubio, R. \& Mas-Ruiz, F. (2007) An empirical analysis of productivity growth in retail services: evidence from Spain. International Journal of Service Industry Management, 18: 52-69.

Sherman, D. 1984. Data Envelopment Analysis as a new managerial audit methodology - test and evaluation. Auditing: A Journal of Practice and Theory, 4: 35-53.

Sorenson, C. \& Kanavos, P. 2011. Medical Technology Procurement in Europe: A crosscountry comparison of current practice and policy. Health Policy, 100: 43-50.

Valdmanis, V.G. 2010. Measuring economies of scale at the city market level. Journal of Health Care Finance, 37: 78-90.

Weng, S.J., Wu, T., Blackhurst, J. \& Mackulak, G. 2009. An extended DEA model for hospital performance evaluation and improvement. Health Services and Outcomes Research Methodology, 9: 39-53. 